\title{
Romėniško laikotarpio emaliuota segè iš viduramžių kapinyno Paūdronyse
}

\author{
MYKOLAS MICHELBERTAS \\ Vilniaus universitetas, Universiteto g. 3, LT-01513 Vilnius \\ El. paštas mykolas.michelbertas@if.vu.lt
}

\author{
MANVYDAS VITKŪNAS \\ Generolo Jono Žemaičio Lietuvos karo akademija, Šilo g. 5a, LT-10322 Vilnius \\ El. paštas manvydas.vitkunas@gmail.com
}

\begin{abstract}
Šiame straipsnyje skelbiama informacija apie XIV a. pabaiga - XV a. datuojamame Paūdronių kapinyne, esančiame Vilniaus apskrityje, Šalčininkų rajono Turgelių seniūnijoje, rastą pasaginę emaliuotą segę. Ji aptikta $2012 \mathrm{~m}$. archeologinių tyrimų metu kapinyno kape Nr. 18, kuriame palaidotas vyresnis nei 20 metų amžiaus asmuo, veikiausiai moteris. Straipsnyje pateikiami detalūs duomenys apie šios segès tipologiją, chronologiją, keliamos versijos, kaip II a. antrąja puse datuota segė galëjo atsidurti viduramžių kapinyno kape.
\end{abstract}

Raktažodžiai: emaliuota segè, senasis geležies amžius, romėniškas laikotarpis, viduramžiai, laidosena, Paūdronių kapinynas, Pietryčių Lietuva

\section{PAŪDRONIŲ KAPINYNAS}

2012 m. buvo pradèti detalūs archeologiniai tyrimai (šių ir vẻlesnių tyrimų vadovas - M. Vitkūnas) Paūdronių kapinyne (unikalus kodas Kultūros vertybių registre - 36748), kuris yra Šalčininkų r., Turgelių sen. Paūdronių kaimo rytiniame pakraštyje, $500 \mathrm{~m}$ ị pietvakarius nuo Lietuvos Respublikos valstybės sienos su Baltarusijos Respublika. Apie 150-180 m i šiaurès rytus nuo kapinyno Merkio kairiojo kranto aukštumos kyšulyje yra Paūdronių piliakalnis (unikalus kodas Kultūros vertybių registre - 25192), vadinamas Pilies kalnu.

Iki 2012 m. Paūdronių kapinynas nebuvo patekęs ị archeologų bei paveldosaugininkų akiratị, nebuvo įtrauktas ị Kultūros vertybių registrą. $2012 \mathrm{~m}$. vasarą iš vietos gyventojo Edvardo Zinevičiaus sužinota, kad Paūdronių kaime yra ardomas laidojimo paminklas. Savavališkai įrengtame karjere kasamas smèlis ir žvyras, randama žmonių kaulų. Skubiai buvo organizuoti archeologiniai tyrinejjimai, kuriuos finansavo leidykla „Versmë“. Praktiką archeologiniuose tyrinejjimuose atliko Lietuvos edukologijos universiteto Istorijos fakulteto studentai, taip pat dirbo savanoriai talkininkai. 
$2012 \mathrm{~m}$. detalių archeologinių tyrinejimų metu kapinyne buvo ištirtos trys perkasos (iš viso - $230 \mathrm{~m}^{2}$ ), aptikti 36 griautiniai kapai [20, 212-219]. 2013 m. Kultūros paveldo departamento užsakymu buvo tikslinamos i privačią žemės valdą patenkančios kapinyno dalies šiaurès vakarinès ir vakarinès ribos [22, 189-191]. Žvalgomųjų archeologinių tyrimų metu buvo ištirtos keturios perkasos (iš viso $-40 \mathrm{~m}^{2}$ ), rasti 2 griautiniai kapai. 2016 m. tyrimus tęsé Generolo Jono Žemaičio Lietuvos karo akademijos Karo mokslų instituto Karo istorijos centras. Ištirta viena $60,9 \mathrm{~m}^{2}$ dydžio perkasa, rasti 4 griautiniai kapai. Taigi iš viso per tris tyrimų sezonus Paūdronių kapinyne ištirtas bendras $330,9 \mathrm{~m}^{2}$ plotas, aptikti 42 kapai [19, 447-449].

Mirusieji Paūdronių kapinyne laidoti paguldyti ant nugaros, ištiestomis kojomis, absoliuti dauguma - galva orientuoti ị vakarus, šiaurès vakarus $230-300^{\circ}$ kryptimi. Tik kape Nr. 30 mirusioji buvo palaidota visiškai priešinga kitiems kapams kryptimi - galva i pietus $180^{\circ}$ kryptimi. Dèl grunto savybių (žvyringas smèlis) beveik visų kapo duobių kontūrai buvo neryškūs. Daugelyje kapų rasti mirusiųjų palaikai yra labai sunykę. Kapuose ir kapinyno teritorijoje aptikta nemažai radinių - sidabrinès LDK monetos, datuojamos XIV a. pabaiga - XV a., žalvarinių apgalvio plokštelių fragmentai, auskarai, plokštinès segès, žalvarinis kabutis, stiklo karoliukai, žalvarinės grandinèlès, pintos žalvarinès apyrankès dalys, žiedai, sagtys, grandys, peiliai, skustuvas, yla, piniginių su žalvariniais ir geležiniais apkalais fragmentai. Kape Nr. 27 (30-40 metų amžiaus vyro) aptikta unikali ịkapé - stambus žalvarinis žvejybos kabliukas. Tačiau, skirtingai nei didesnejje dalyje kitų to meto Lietuvos kapinynų, čia visiškai nerasta ginklų (ietigalių, kirvių ir kt.). Krikščionims būdinga laidojimo kryptis (galva ị vakarus) ir senųjų baltiškų laidojimo papročių reliktas - įkapių gausa liudija ši kapinyną palikusios viduramžių bendruomenès religinị sinkretizmą.

Pats netikéčiausias radinys XIV-XV a. datuojamame Paūdronių kapinyne buvo kape Nr. 18 aptikta žalvarinè emaliuota pasaginè segé, visiškai iškrentanti iš bendro viduramžių epochos radinių konteksto ir reprezentuojanti senąji geležies amžių (roménišką laikotarpi - I-IV a.).

\section{KAPAS NR. 18}

2012 m. tiriant perkasą Nr. 1, $52 \mathrm{~cm}$ gylyje buvo atidengti griaučių fragmentai. Jie buvo aptikti dar preparuojant kapą Nr. 17. Kapas Nr. 18 iš dalies pateko po kairiuoju kape Nr. 17 palaidoto mirusiojo šonu. Kasant duobę kapui Nr. 17, kapas Nr. 18 (1 pav.) buvo apardytas. Kaukolè, dešiniosios dubens dalies, dešiniosios kojos ir kai kurie kiti kaulai neišliko. Mirusioji buvo palaidota paguldyta ant nugaros, galva ị vakarus $260^{\circ}$ kryptimi. Rankų padètis neaiški (išlikę tik žastikauliai), kojos (išliko tik kairiosios kojos kaulai) buvo ištiestos, kairioji koja truputi palenkta į vidų. Karsto pėdsakų neaptikta, kapo duobès kontūrai neryškūs [21, 19-20].

Kaukolès (neišlikusi) srityje rasta pasaginè segè, puošta raudonu emaliu. Gali būti, kad segè buvo padèta po mirusiosios galva (panašiai kaip tame pačiame kapinyne kape Nr. 21 po mirusiosios galva buvo rastos trys viena ant kitos sudètos apskritos skardinès segès). Segè padèta emaliu puošta puse ị apačią (2 pav.), jos geležinio liežuvèlio likučiai labai paveikti korozijos. Kitų ikapių kape Nr. 18 nerasta.

Palaikų iš Paūdronių kapinyno antropologinę analizę atlikęs Vilniaus universiteto Medicinos fakulteto Anatomijos, histologijos ir antropologijos katedros prof. dr. Rimantas Jankauskas nustatè, kad kape Nr. 18 palaidotas asmuo buvo vyresnis nei 20 metų amžiaus, spejjama - moteris $[9,161]$. 


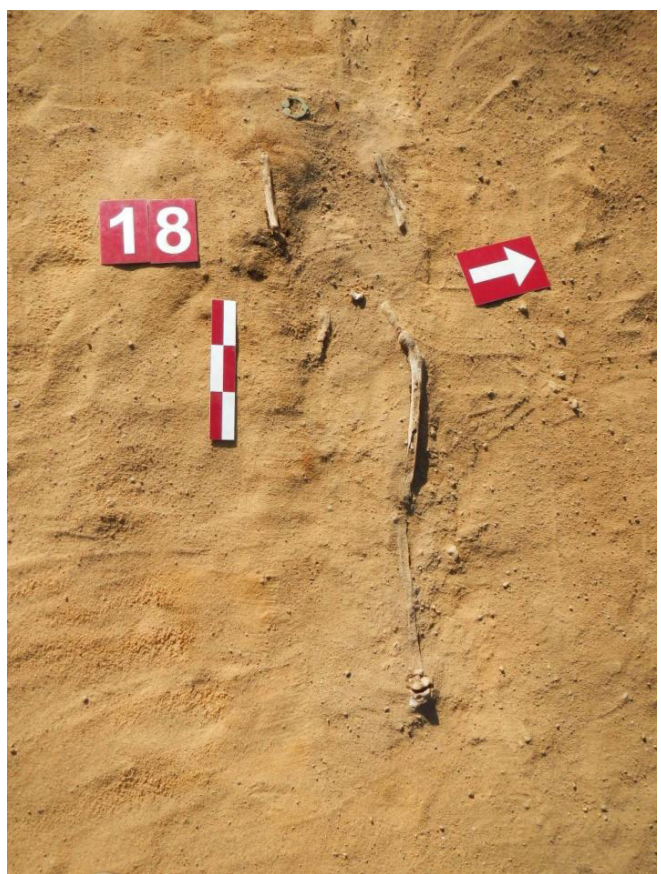

1 pav. Paūdronių kapinyno kapas Nr. 18. Bendras vaizdas. Manvydo Vitkūno nuotr.

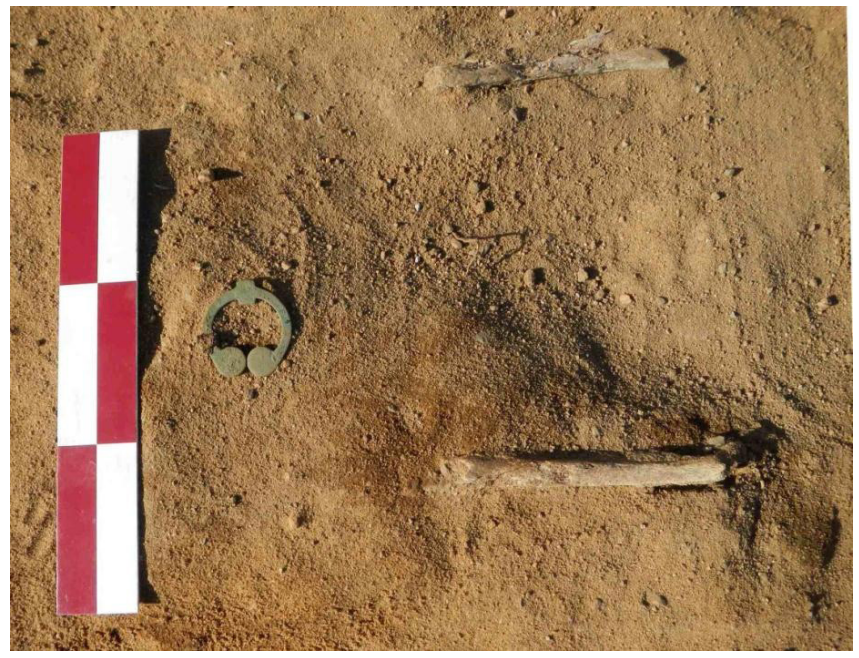

2 pav. Segè kape Nr. 18 in situ. Manvydo Vitkūno nuotr.

Segè, kaip ir kiti Paūdronių kapinyno tyrimų metu rasti radiniai, perduota Trakų istorijos muziejui (1). Galbūt ateityje dalis jų bus eksponuojama šio muziejaus filiale - Medininkų pilyje, kuri yra vos $12 \mathrm{~km}$ nuo Paūdronių kapinyno.

(1) Segès inventorinis numeris Trakų istorijos muziejaus fonduose - AP778. 


\section{SEGĖS APIBŪDINIMAS}

Kape Nr. 18 rastos segès (3-4 pav.) lankelio viršutineje dalyje yra vertikalus stačiakampis, kurio vidus užpildytas raudonu emaliu. Abu segès galai praplatinti, apskriti, juose yra kryželio formos užapvalintais galais ornamentai, taip pat užpildyti raudonu emaliu. Dešinèje segès pusèje, prie pat apvalaus galo, išlikę labai smarkiai korozijos paveikto geležinio liežuvèlio fragmentai. Priešingoje lankelio puseje taip pat yra labai menki liežuvèlio likučiai. Segès aukštis $61 \mathrm{~mm}$, plotis $55 \mathrm{~mm}$. Lankelio skersmuo $6 \mathrm{~mm}$, storis $2,5 \mathrm{~mm}$. Lankelis pusapvalio skersinio pjūvio. Viršutineje segès dalyje esančio vertikalaus stačiakampio aukštis $15,5 \mathrm{~mm}$, plotis $12 \mathrm{~mm}$, storis identiškas lankelio storiui. Vidinès emaliu užpildytos ertmès dydis $12 \times 8 \mathrm{~mm}$. Apatinèje dalyje esantys paplatinti apskriti galai yra $19 \mathrm{~mm}$ skersmens, jų storis identiškas lankelio storiui. Emaliu užpildytų kryželio formos ornamentų ilgis $16 \mathrm{~mm}$. Liežuvèlis galèjo būti apie $63 \mathrm{~mm}$ ilgio, $8 \mathrm{~mm}$ pločio. Kita segès pusė lygi, jokių ịspaudų ar ornamentų nèra. Segė jau pateko ì specializuotą mokslinę literatūrą - ji trumpai yra pristatyta kituose šio straipsnio autorių darbuose $[15,78 ; 20$, 215-216, pav. 4].

Trakų istorijos muziejuje buvo atlikti metalų sudèties (2) cheminiai tyrimai (tyré Simonas Senulis), segè restauruota (restauratorè Renata Mečkovskienè) (3). Tyrimai rodo, kad segés korpusas yra pagamintas iš daugiakomponenčio vario lydinio, kurị sudaro varis $(\mathrm{Cu}, 74,874 \%)$, cinkas $(\mathrm{Zn}$, $7,562 \%)$, alavas ( $\mathrm{Sn}, 6,857 \%)$, švinas $(\mathrm{Pb}$, $9,766 \%$ ) ir geležis (Fe, 0,941\%). Taigi pagrindinis komponentas yra varis, jungiantys metalai - alavas, cinkas ir švinas, aptikta ir nedidelè geležies priemaiša.
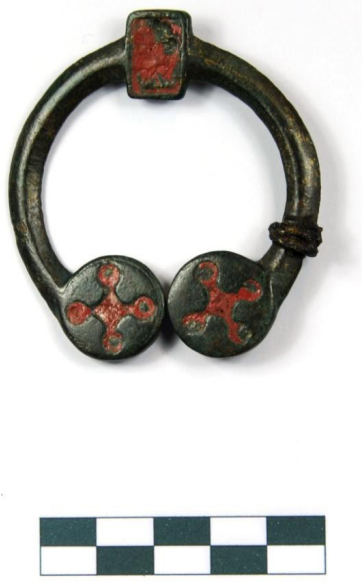

3 pav. Segè po restauravimo. Deivido Abramenkos nuotr.
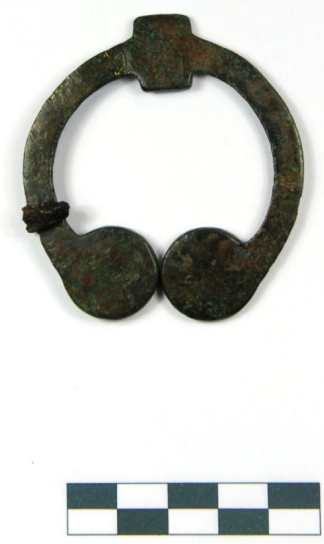

4 pav. Segè po restauravimo (kita pusè). Deivido Abramenkos nuotr.

(2) Buvo atlikti ir emalio sudèties tyrimai, tačiau jie nepakankamai tikslūs, todèl šiame straipsnyje neskelbiami.

(3) Autoriai nuoširdžiai dèkoja Simonui Senuliui už cheminius metalo sudèties tyrimus, Renatai Mečkovskienei - už segès restauravimą. 
İdomu tai, kad iš panašios sudèties vario lydinio buvo pagaminta segè, rasta Bargluv Dvorny (Bargłów Dworny) kapinyno (Palenkès vaivadija, Augustavo apskritis) kape Nr. 4a. Šios segès korpuso lydinị sudaro varis (Cu, 81,71\%), cinkas (Zn, 9,78 \%), alavas (Sn, 3,71\%), švinas $(\mathrm{Pb}, 2,94 \%)$, taip pat aptikta geležies, sidabro ir aukso priemaišu [6, 334, ryc. 11a, 11c]. Ir trikampio kabučio su emaliu iš Andulių kapinyno metalinio korpuso sudetis buvo labai panaši: varis (Cu, 86,169\%), alavas (Sn, 6,529 \%), cinkas (Zn, $5,659 \%)$, švinas ( $\mathrm{Pb}, 1,137 \%)$, taip pat rasta stibio, geležies ir nikelio priemaišų $[5,123$, tab. I]. Paprastai vario lydiniai, kuriuose cinko tarp jungiančių metalų yra daugiau negu alavo, vadinami žalvariniais.

Ištirtas ir Paūdronių segès liežuvèlis. Jis pagamintas iš geležies ( $\mathrm{Fe}, 82,685$ \%) su vario $(\mathrm{Cu}, 13,073 \%)$, cinko $(\mathrm{Zn}, 3,921 \%)$ ir labai nedidele alavo (Sn, 0,321 \%) priemaiša. Lietuvoje pasaginè segè su geležiniu liežuvèliu rasta tyrinejjant Pakalnių pilkapyno (Vilniaus r.) pilkapio Nr. 7 kapą Nr. 2, datuojamą II a. pabaiga - III a. pradžia [18, 54-58, 70, pav. 14].

Tikslių Paūdronių segès analogų Lietuvos teritorijoje nerasta. Šią segę šiek tiek primena segė iš Mozūrų kapinyno (nurodoma vietovė Moythienen; dab. Mojtyny, Varmijos Mozūrų vaivadija, Mrongovo apskritis) kapo Nr. 35 [7, 246, Abb. 189b; 16, 8, Abb. 9]. Pastaroji ant apskrito pjūvio lankelio turi emaliuotą stačiakampị, tačiau galai puošti raudono emalio apskritimais. Paūdronių segès galų puošimas kryželiais ją daro artimą pasaginei emaliuotai segei, aptiktai Vilniaus krašte (tiksli radimo vieta nežinoma) [11, 46-47, lent. XI: 2]. Ši pasaginès segès dalis turi apskrito pjūvio lankelị ir profiliuotą žiedą lankelio viduryje. Išlikęs segès galas yra puoštas raudono emalio kryželiu.

Vilniaus krašto segei analogų Lietuvos archeologineje medžiagoje taip pat nèra. Šią segę lenkų tyrèja A. Jablonska priskyrẻ pasaginių segių su emaliu I tipui, nurodydama, kad šis tipas negalejo pasirodyti ir būti naudojamas anksčiau negu B2/C1 periodu [8, 123-125, 138-141, tabl. II]. E. Gorochovskis Vilniaus krašto segę priskiria III serijai ir datuoja II a. antrąja puse [23, 32, рис. 6: 5, 7a].

I Vilniaus krašto segę panašių radinių aptikta Vidurio Padnieprèje, pvz., Trostianeco (Тростянец, , Ukraina, Čerkasų sritis, Kanevo rajonas) vietovejje rasta segè turi apskrito pjūvio lankelį, bet be profiliuoto žiedo [24, 66, табл. 7: 5]. Jos galai yra puošti kryželiais su raudonu emaliu. Panašios segès iš Lipliavès (Ліпля́ве, Ukraina, Čerkasų sritis, Kanevo rajonas) galai puošti rozete su raudonu emaliu [24, 70, табл. 13: 5]. Vilniaus krašto segei artimų egzempliorių rasta ir Lenkijoje, Mozūrų teritorijoje. Antai Babientų (Babięta, Varmijos Mozūrų vaivadija, Mrongovo apskritis) kapinyno kape Nr. 57 buvo aptikta nedidelè segè apskrito pjūvio lankeliu ir galais su duobutèmis, puoštomis emaliu $[16,80$, Abb. 8].

Šios grupès segių datavimo klausimą galutinai išsprendè radinys Maslomečo (Masłomęcz, Lenkija, Liublino vaivadija, Hrubiešuvo apskritis) kapinyno kape Nr. 294 [10, 188, Abb. 45]. Šiame labai turtingame moters kape buvo aptikta ir bronzinè pasaginė segè apskrito pjūvio lankeliu su profiliuotu žiedu ant jo, kryželiais su raudonu emaliu puoštais galais. Ši segė yra labiausiai panaši i Vilniaus krašto segę. Maslomečo kapinyno kapas Nr. 294 yra datuojamas B2/C1 periodu, t. y. II a. antrąja puse.

Manytume, kad tiek Vilniaus krašto, tiek ir Paūdronių segę galima priskirti tam pačiam laikotarpiui, t. y. B2/C1 periodui.

Chronologiniu ir tipologiniu atžvilgiu Paūdronių segei yra artimos pasaginès emaliuotos segès iš Vidurio Lietuvos [13, 18-26, pav. 1], aptiktos Sargėnų kapinyno (Kauno m.) 
kape Nr. 203 [11, 46-47, lent. XI: 1], Marvelès kapinyno (Kauno m.) kapuose Nr. 76 ir 110 [1, 121-123, pav. 10: 1, 10: 2; 3, 35, 41, Taf. XXXIII, XLII, CLXXVIII: 4, CLXXXII: 1] ir atsitiktinai Rumšiškèse, Kaišiadorių r. [14, 93, pav. 25]. Šių segių dydis yra nuo 5,4 ×5,1 cm iki $6,6 \times 6,1 \mathrm{~cm}$. Visų segių lankeliai yra trikampio pjūvio, jų viršuje yra stačiakampiai su emaliu. Skiriasi segių apskritų galų puošyba. Dviejų segių (Sargènai, Rumšiškès) apskritimai puošti raudono emalio kryželiais, vienos (Marvelè, k. Nr. 76) - apskritimu su raudonu emaliu. Marvelès kapo Nr. 110 segès galai puošti žalsvo stiklo mase su trimis balto emalio (akmenèlių?) akutemis.

Pagal kitas ịkapes Sargènų ir Marvelès segès yra datuojamos B2/C1-C1a periodu, t. y. II a. antrąja puse - III a. pradžia. Spejjama, kad vienas iš ankstyvų pasaginių emaliuotų segių gamybos centrų galèjo būti dabartinio Kauno teritorijoje bei apylinkèse.

Kaip matome, Lietuvoje aptikta nemažai ankstyvų pasaginių segių su emaliu. Tokioms segèms priklauso ir dar vienas radinys iš Mozūrų regiono (Lenkija) rytinio pakraščio. Bargluv Dvorny (Bargłów Dworny) vietoveje (Palenkès vaivadijoje, Augustavo apskrityje) rasta pasaginè emaliuota segè turi trikampio pjūvio lankelị su rombu viršuje, galai puošti raudono emalio kryželiais [12, 63-64, tabl. XXI: 5]. Ši segè priskiriama II a. pabaigai - III a. pirmajai pusei $[4,89]$. Taigi galima kalbèti apie panašių to paties laikotarpio segių gamybą Mozūruose, Vidurio ir Rytų Lietuvoje.

\section{VERSIJA: ANTRINIS PANAUDOJIMAS?}

Kaip II a. datuojama segè atsidūrè XIV-XV a. kapinyne? Galimos kelios versijos. Pirma - tai atsitiktinis radinys, nieko bendra neturintis su kapinyne palaidotais žmonémis; kape jis atsirado atsitiktinai užpilant kapo duobę žemėmis. Antra - šioje vietoje būta senojo geležies amžiaus kapų; ši versija mažai tikètina, nes, ištyrus daugiau nei $330 \mathrm{~m}^{2}$ plotą, nerasta jokių kitų romėniško laikotarpio radinių, o pats kapas jokiais požymiais (kapų horizontas, laidojimo kryptis ir kt.) neišsiskiria iš bendro Paūdronių kapinyno konteksto. Trečia - tai antrinis segès panaudojimas: senojo geležies amžiaus laikotarpio radinys buvo surastas viduramžiais ir kurị laiką vèl naudotas.

Šio straipsnio autoriai linkę laikytis trečiosios versijos - tai romėniško laikotarpio dirbinio antrinis panaudojimas viduramžiais, juolab kad Paūdronių viduramžių kapinynas yra šalia Paūdronių piliakalnio (kuris iki šiol archeologų detaliau netyrinètas) [2, 426427]. Piliakalnyje archeologinių žvalgymų metu rasta brūkšniuotosios keramikos šukè. Paūdronių piliakalnis preliminariai datuotas I a. pirmąja puse, nors neatmesta galimybè, kad jis galejo būti naudotas ir vèliau [17, 119]. Piliakalnio papèdèje, greta Merkio upès, veikiausiai buvo senovès gyvenvietè. Čia senajame geležies amžiuje gyvenę žmonès galejo pamesti segę, o ją radę viduramžių gyventojai - vèl naudoti.

\section{APIBENDRINIMAS}

B2/C1 periodu (apie 150-200 m. po Kr.) datuojama Paūdronių pasaginė segè buvo aptikta itin neịprastoje vietoje - XIV-XV a. viduramžių kapinyno kape. Šis radinys ne tik retas ir vertingas moksliniam pažinimui. Išskirtinès jo naudojimo aplinkybès: šis pirmaisiais amžiais po Kristaus pagamintas ir naudotas papuošalas veikiausiai buvo pamestas, vèliau aptiktas viduramžiais ir vẻl naudojamas, taip netikètai pratęsiant šių papuošalų nešiojimo tradiciją. Paūdronių segè, naudota dviejų daugiau nei tūkstančio metų skiriamų epochų žmonių, tarsi simboliškai sujungè šioje vietovejje prie Merkio upės aukštupio gyvenusias brūkšniuotosios keramikos kultūros ir viduramžių Lietuvos žmonių bendruomenes. 
Paūdronių segè ne tik papildè emaliuotų dirbinių radaviečių sąrašą. Ji aptikta Pietryčių Lietuvoje, kur tokių dirbinių iki šiol buvo rasta itin mažai. Šiuo metu Lietuvos teritorijoje jau žinomi 47 emaliuoti dirbiniai, priskiriami vadinamiesiems ,,barbariškiesiems emaliams“. Jie pagaminti meistrų juvelyrų, gyvenusių Vakarų, Vidurio ir Rytų Lietuvoje, Užnemunejje ir Žemaitijoje. Tarp emaliuotų daiktų yra žirgo kamanų puošmenos, geriamųjų ragų juostos-rankenos, įvairių tipų segès, apyrankès, kaklo bei krūtinès papuošalai. Tiek vakarinių, tiek rytinių baltų genčių meistrai prisidejjo prie emaliuotų dirbinių paplitimo didžiulèje Rytų Europos teritorijoje. Daiktai su emaliu buvo didelis ir vertingas baltų genčių indèlis ị romėniško laikotarpio (I-V a. I pusè) europinio Barbaricumo materialinę ir dvasinę kultūrą.

Gauta 20170320

Priimta 20170329

\section{Literatūra}

[1] ASTRAUSKAS, Audrius. Marvelès kapinyno (II-VII a. kapai) tyrinejjimai 1992 ir 1993 metais. Archeologiniai tyrinejimai Lietuvoje 1992 ir 1993 metais. Vilnius: „Diemedžio“ l-kla, 1994, p. 120-124.

[2] BAUBONIS, Zenonas; ZABIELA Gintautas (sudarytojai). Lietuvos piliakalniu atlasas. T. II. Vilnius, 2005.

[3] BERTAŠIUS, Mindaugas. Marvelè. Ein Graberfeld Mittellitauens. I band. Kaunas: Kauno technologijos universitetas, 2005.

[4] BIEGEL, Gerd; JASKANIS, Jan. Die Balten. Die nördlichen Nachbarn der Slawen. Freiburg i. Br.: Schillinger, 1987.

[5] BITNER-WRÓBLEWSKA, Anna; BLIUJIENĖ, Audronè. Efektowny napierśnik z emalią z cmentarzyska w Anduln, zachodnia Litwa. Antyk i barbarzyńcy: ksiegga dedykowana Profesorowi Jerzemu Kolendo w siedemdziesiąta rocznicę urodzin. Warszawa: Instytut Archeologii Uniwersytetu Warszawskiego, 2003, s. 121-132.

[6] BITNER-WRÓBLEWSKA, Anna; STAWIARSKA, Teresa. Badania technologiczne wschodnioeuropejskich zabytków zdobionych emalią. Bałtowie i ich sąsiedzi: Marian Kaczyński in memoriam. Seminarium Bałtyjskie. T. II. Warszawa: Państwowe Muzeum Archeologiczne, 2009, s. 303-351.

[7] GAERTE, Wilhelm. Urgeschichte Ostpreußens. Königsberg, 1929.

[8] JABŁOŃSKA, Antonina. Zapinki podkowiaste z emalią w Europie PółnocnoWschodniej w okresie wpływów rzymskich. Acta Baltico-Slavica. T. 21. Warszawa: Instytut Slawistyki PAN, 1992, s. 116-165.

[9] JANKAUSKAS, Rimantas. Žmonių palaikų iš Paūdronių (2012 m. tyrinejjimai) antropologinio tyrimo rezultatai. Iš: Vitkūnas, Manvydas. Paūdronių kapinyno (36748), Turgelių sen., Šalčininkų r., archeologinių detaliųjų tyrimų 2012 m. ataskaita. Lietuvos istorijos instituto Rankraštynas, f. 1, b. 6182.

[10] KOKOWSKI, Andrzej; LEIBER, Christian. Schätze der Ostgoten. Stuttgart: Theiss Verlag, 1995.

[11] KULIKAUSKAS, Pranas. Emaliuotieji dirbiniai Lietuvoje. Vytauto Didžiojo kultūros muziejaus metraštis. T. I. Kaunas, 1941, p. 43-63.

[12] MARCINIAK, Józef. Dwa cmentarzyska ciałopalne z okresu rzymskiego w 
Judzikach i Bargłowie Dwornym w pow. augustowskim. Wiadomości Archeologiczne. T. XVII. Warszawa: Państwowe Muzeum Archeologiczne, 1950, s. 47-76.

[13] MICHELBERTAS, Mykolas. Centrinè Lietuva - romėniškojo laikotarpio emaliuotų dirbinių gamybos centras. Vidurio Lietuvos archeologija. Etnokultūriniai ryšiai. Vilnius: Žalioji Lietuva, 1996.

[14] MICHELBERTAS, Mykolas. Prekybiniai ryšiai su Romos imperija. Lietuvos gyventoju prekybiniai ryšiai I-XIII a. Vilnius: Mintis, 1972, p. 5-125.

[15] MICHELBERTAS, Mykolas. Romeniškojo laikotarpio emaliuoti dirbiniai Lietuvoje. Vilnius: Vilniaus universiteto l-kla, 2016.

[16] MOORA, Harri. Zur Frage nach der Herkunft des ostbaltischen emailverzierten Schmuks. Suomen Muinaismuistoyhdistyksen Aikakauskirja. T. XL. Helsinki, 1934, s. 74-90.

[17] STRAZDAS, Arūnas. Nauji piliakalniai. Archeologiniai tyrinejjimai Lietuvoje 1998 ir 1999 metais. Vilnius: „Diemedžio“ 1-kla, 2000, p. 118-120.

[18] VAITKEVIČIUS, Vykintas. Pakalnių pilkapiai (Vilniaus r.). Lietuvos archeologija. T. 26. Vilnius: „Diemedžio“1-kla, 2004, p. 47-72.

[19] VITKŪNAS, Manvydas. Medieval Old Cemeteries of the Provinces. A Hundred Years of Archeological Discoveries in Lithuania. Vilnius: Society of the Lithuanian Archeology, 2016, p. 442-453.

[20] VITKŪNAS, Manvydas. Paūdronių kapinynas. Archeologiniai tyrinėjimai Lietuvoje 2012 metais. Vilnius: Lietuvos archeologijos draugija, 2013, p. 212-219.

[21] VITKŪNAS, Manvydas. Paūdronių kapinyno (36748), Turgelių sen., Šalčininkų r., archeologinių detaliųjų tyrimų 2012 m. ataskaita. Lietuvos istorijos instituto Rankraštynas, f. 1, b. 6182.

[22] VITKŪNAS, Manvydas. Paūdronių senkapis. Archeologiniai tyrinëjimai Lietuvoje 2013 metais. Vilnius Lietuvos archeologijos draugija, 2014, p. 189-191.

[23] ГОРОХОВСКИЙ, Євген. Підковоподібні фібули Середнього Подніпров’я з виїмчастою емаллю. Археологія. Вип. 38. Київ, 1982, с. 16-36.

[24] КОРЗУХИНА, Галя. Предметы убора с выемчатыми эмалями V - первой половины VI в. н. э. в Среднем Поднепровье. Археология СССР. Свод археологических источников. Выпуск Е1-43. Ленинград: Наука, 1978. 
MYKOLAS MICHELBERTAS, MANVYDAS VITKŪNAS

\section{The Roman Period Enamel Brooch from the Medieval Burial Ground in Paūdronys}

Summary

The paper provides information on a horseshoe-shaped enamel brooch dated to the $\mathrm{B} 2 / \mathrm{C} 1$ stage (around AD 150-200), which was found in the Paūdronys burial ground dating back to the late fourteenth-fifteenth century and situated in Turgeliai eldership of the Šalčininkai district, the county of Vilnius. It was discovered in the course of the archaeological research of 2012 in grave No. 18 (Fig. 1-2), which belongs to a person older than 20 years of age and most likely a woman. The upper part of the bow of the brooch (Fig. 3-4) features a vertical rectangle with its interior filled with red enamel. Both terminals of the brooch are broadened and round; they feature ornaments in the shape of little crosses with rounded terminals; they are also filled with red enamel. The remains of an iron pin were found next to the brooch. The body of the brooch is made of a multicomponential copper alloy: copper $(\mathrm{Cu}$, $74.874 \%)$, zinc $(\mathrm{Zn}, 7.562 \%)$, tin ( $\mathrm{Sn}, 6.857 \%)$, lead $(\mathrm{Pb}, 9.766 \%)$, and iron $(\mathrm{Fe}$, $0.941 \%)$. The pin is made of iron ( $\mathrm{Fe}, 82.685 \%)$ blended with copper $(\mathrm{Cu}, 13.073 \%)$, zinc ( $\mathrm{Zn}, 3.921 \%)$, and a very small amount of tin $(\mathrm{Sn}, 0.321 \%)$. No exact equivalents for the brooch of Paūdronys have been found on the territory of Lithuania. Similar brooches were discovered in certain localities of Lithuania and a wide area that stretches from Masuria (Poland) to the Middle Dnieper region (Ukraine). From a chronological and typological perspective, the horseshoe-shaped enamel brooches from Central Lithuania (brooches from the burial grounds of Marvele and Sargenai and the brooch accidentally found in Rumšiškes) are akin to the brooch of Paūdronys. The Roman period brooch was found in Paūdronys in an especially unusual place - a grave of a medieval burial ground dating to the fourteenth-fifteenth century. This piece of jewellery, which had been made and used in the first centuries $\mathrm{AD}$, was most likely lost and eventually found in the Middle Ages when it was fitted for secondary use, thus unexpectedly extending its wearing tradition.

Keywords: enamel brooch, Old Iron Age, Roman period, Middle Ages, burial customs, Paūdronys burial ground, Southeast Lithuania. 